\title{
A GESTÃO DO CONHECIMENTO SOB A PERSPECTIVA DAS SETE DIMENSÕES: O CASO DO PROJETO PERFIS PROFISSIONAIS PARA O FUTURO DA INDÚSTRIA
}

\author{
LA GESTIÓN DEL CONOCIMIENTO BAJO LA \\ PERSPECTIVA DE LAS SIETE DIMENSIONES: EL CASO \\ DEL PROYECTO PERFILES PROFESIONALES PARA EL \\ FUTURO DE LA INDÚSTRIA.
}

Karoline Aparecida Scroch Sato - karoline.scroch@gmail.com Mestre em Ciência, Gestão e Tecnologia da Informação pela Universidade Federal do Paraná (UFPR).

Helena Nunes Silva - helenanuness@gmail.com Doutora em Engenharia de Produção pela Universidade Federal de Santa Catarina (UFSC). Docente da Universidade Federal do Paraná (UFPR).

Isabela Drago - isabeladrago@gmail.com Mestre em Ciência, Gestão e Tecnologia da Informação pela Universidade Federal do Paraná (UFPR).

\section{RESUMO}

Introdução: Organizações que atuam em estudos prospectivos, são intensas na criação e compartilhamento do conhecimento e um dos principais desafios está em tornar coletivo o conhecimento individual.

Objetivo: Analisar por meio das sete dimensões do conhecimento propostas por Terra (2001, 2005) o alinhamento do projeto Perfis Profissionais para o Futuro da Indústria, possibilitando um ambiente propício à criação e ao compartilhamento do conhecimento.

Metodologia: Pesquisa descritiva fundamentada em um estudo de caso.

Resultados: A alta administração atua como facilitadora; a cultura organizacional propicia o compartilhamento estimulando a socialização, experimentação e valorização das ideias; 
apesar da estrutura hierárquica, há incentivo à participação; há um processo de seleção voltado a especialidades e qualificações diversas, com constantes capacitações; a organização utiliza diversas tecnologias facilitando a troca de informações e conhecimentos; não existem métricas definidas para avaliação dos resultados e, finalmente, o aprendizado com o ambiente se dá por meio de parcerias, treinamentos e da própria diversidade cultural. Conclusões: Conclui-se que a equipe do Projeto tem um ambiente propício à criação e compartilhamento de conhecimento o qual é fundamental na prospecção de oportunidades de inovação e na geração de respostas às demandas e necessidades socioindustriais para o futuro da indústria paranaense.

Palavras-chave: Compartilhamento de conhecimentos. Criação de conhecimento. Gestão do conhecimento.

\section{INTRODUÇÃO}

A transição da sociedade industrial para a do conhecimento transformou de maneira significativa os modos de produção. A fabricação de objetos deixa de ter papel central frente ao recurso conhecimento, que passa a ser considerado o motor da nova economia passando dos insumos tangíveis para os intangíveis e da força para o conhecimento (CARVALHO, 2000). Devido a estas mudanças torna-se necessário que se conheçam e explorem novas técnicas e métodos de gestão que possibilitem às organizações maior vantagem competitiva, gerando novos produtos e serviços.

No ambiente das organizações e dos negócios, 0 interesse pelo conhecimento acentua-se com a constatação de que o valor de mercado de algumas empresas chega a ser inúmeras vezes maior do que o valor do patrimônio financeiro e físico que possuem. As ações valem tanto porque incorporam valores intangíveis, como a marca e a imagem, a capacidade de inovação, o talento e a competência de seus colaboradores. Esse valor intangível só é possível pela incorporação de novas experiências, de reflexão, da aprendizagem contínua e compartilhada (TONET; DA PAZ, 2006).

O desafio das organizações desta nova sociedade é, portanto, gerenciar o seu ambiente para que seja possível criar conhecimento. "Empresas criadoras de conhecimento, seriam, pois, aquelas que criam, sistematicamente, novos conhecimentos, disseminam pela organização inteira e, rapidamente, os incorporam as novas tecnologias e produtos." (TERRA, 2001, p. 78). A criação do conhecimento acontece por meio de processos de conversão do conhecimento tácito, que está na 
mente dos colaboradores, para o conhecimento explícito, formalizado. É preciso, portanto, que exista o compartilhamento dos conhecimentos para que gere aprendizado organizacional.

Neste ambiente de grandes transformações faz-se necessário que as organizações tenham uma postura pró-ativa gerenciando o recurso conhecimento para antecipar mudanças. $\mathrm{Na}$ busca de respostas, algumas organizações utilizam técnicas e ou metodologias para auxiliar nas decisões das ações presentes com objetivos futuros mais precisos. Neste sentido, os estudos prospectivos auxiliam na diminuição das incertezas frente ao futuro.

Santos et al. (2004) afirmam que tais estudos procuram entender o que orienta o futuro, visando promover transformações, negociar espaços e dar direção e foco às mudanças. Uma das abordagens utilizadas pelas organizações é a prospectiva, que "induz à reflexão coletiva, à luz das tendências de mudanças do ambiente local e global" (FEDERAÇÃO DAS INDÚSTRIAS DO ESTADO DO PARANÁ, 2010, p. 8), devendo conjugar as mudanças possíveis e desejáveis com a preparação para a ação, ou seja, a elaboração e avaliação de mudanças possíveis para se preparar para as mudanças esperadas e provocar estas mudanças (GODET, 2000). Esta abordagem utiliza a aplicação de processos sistemáticos e participativos que possibilitam a construção de conhecimentos conduzindo, pelo resultado gerado, à criação de conhecimentos compartilhados de futuro, a médio e longo prazo e identificação de ações que necessitam ser realizadas no presente, para se alcançar o futuro proposto.

A prospectiva antecipa transformações, sistematizando informações relevantes para a tomada de decisão de modo a tornar realidade o futuro desejado de maneira compartilhada. Os estudos prospectivos tiveram início no Japão em 1970 e se expandiram fortemente para outros países a partir da segunda metade da década de 90 . No Brasil, as atividades de prospecção em nível nacional tiveram início em 1996 com o Projeto Brasil 2020 elaborado pela SAE - Secretaria de Assuntos Estratégicos e também se expandiram.

Considerando as iniciativas no Estado do Paraná, destacam-se os Observatórios de Prospecção do Sistema FIEP - Federação das Indústrias do Estado do Paraná. Acompanhando as tendências globais e com as incertezas frente ao futuro, o Observatório de Prospecção e Difusão de Tecnologia do Serviço 
Nacional de Aprendizagem Industrial - SENAI do Sistema FIEP preocupou-se com a questão do futuro da indústria paranaense. Iniciou um processo reflexivo com o objetivo de fazer uma análise da situação atual e futura e identificar quais seriam os setores portadores de futuro que poderiam situar o Paraná em posição competitiva, antecipando ações.

Para tal, iniciou em 2006 um projeto intitulado Setores Portadores do Futuro para o Estado do Paraná com o objetivo de analisar a posição dos setores industriais do Estado em relação às tendências apontadas em um horizonte de dez anos. Com o resultado deste projeto, foi possível elaborar as rotas tecnológicas dos setores identificados, projeto intitulado - Rotas Estratégicas para o Futuro da Indústria Paranaense, que teve como objetivo apontar caminhos de construção do futuro para cada um dos setores e áreas mais promissores para a indústria do Paraná no horizonte de 2015 (FEDERAÇÃO DAS INDÚSTRIAS DO ESTADO DO PARANÁ, 2010).

Os resultados do projeto das rotas estratégicas evidenciaram a necessidade de formação profissional alinhada com as visões e as tecnologias-chave para o desenvolvimento do Estado. Desta necessidade surgiu o projeto Perfis Profissionais para o Futuro da Indústria. Projeto este conduzido pelo Observatório de Prospecção e Difusão de Iniciativas Sociais do SESI/PR e o Observatório de Prospecção e Difusão de Tecnologia do SENAI/PR, que tem como objetivo identificar os perfis profissionais que serão demandados no futuro pelas empresas e pela sociedade (FEDERAÇÃO DAS INDÚSTRIAS DO ESTADO DO PARANÁ, 2010).

Neste sentido, considerando que as organizações que atuam em estudos prospectivos são intensas na criação e compartilhamento do conhecimento e que um dos principais desafios das organizações está em tornar coletivo o conhecimento individual, o presente artigo se propõe a analisar, a partir de um estudo de caso, o projeto Perfis Profissionais do Futuro em alinhamento às sete dimensões do conhecimento propostas por Terra (2001 e 2005) a fim de propiciar um ambiente a criação e ao compartilhamento do conhecimento entre os participantes do projeto. 


\section{CRIAÇÃO DO CONHECIMENTO}

Nas últimas décadas as organizações se conscientizaram da importância da revisão dos modelos de gestão, em especial as organizações brasileiras que sofreram um atraso em relação a situação mundial. Iniciou-se, portanto, uma busca de novos modelos de gestão que atendessem as tendências mundiais em um mercado cada vez mais globalizado e competitivo e que garantisse a sobrevivência das mesmas (SANTOS et al., 2001). Toda esta evolução dos modelos de gestão foi importante na introdução e disseminação de práticas administrativas que de certa forma podem ser percebidas como esforços para o gerenciamento de um recurso até então não reconhecido como um ativo importante: o conhecimento organizacional. Esta se torna a característica mais marcante, a valorização do capital intelectual e não mais da força para movimentar a economia. Os ativos convencionais, físico e financeiro certamente não desaparecerão, porém, o ativo conhecimento, face a importância crescente será o ativo mais importante para as organizações (STEWART, 2002). Assim, com a evolução das sociedades e os desafios impostos da constante revisão dos modelos de gestão, constata-se que as organizações precisam enfrentar estas mudanças e necessitam repensar estruturas voltadas para a valorização do recurso conhecimento, pois a criação e o compartilhamento dos ativos intangíveis passam a ser decisivos na competitividade das mesmas.

Para vencerem e se manterem competitivas as organizações precisam pensar maneiras e práticas para criar conhecimento organizacional e gerar aprendizagem. "Os novos conhecimentos sempre se originam nas pessoas" (NONAKA, 2000, p. 31). A criação do conhecimento para as organizações, portanto, envolve a capacidade de adquirir, criar, acumular e explorar o conhecimento. Esta "criação acontece quando o conhecimento dos indivíduos passa a ser cristalizado como parte da organização" (NONAKA; TAKEUCHI, 1997, p. 83). Porém, a criação não é uma "simples compilação de fatos, mas um processo humano singular e irredutível, que não se produz com facilidade" (VON KROGH; ICHIJO; NONAKA, 2001, p. 15).

Para que a construção de conhecimento exista é necessário um relacionamento sinérgico entre o conhecimento tácito e o explícito e a elaboração de processos sociais que possibilitem a criação de novos conhecimentos por meio da 
conversão do conhecimento tácito em conhecimento explícito (NONAKA; TAKEUCHI, 1997). "Empresas criadoras de conhecimento, seriam, pois, aquelas que criam, sistematicamente, novos conhecimentos, disseminam-nos pela organização inteira e, rapidamente, os incorporam as novas tecnologias e produtos." (TERRA, 2001, p. 78).

O processo de criação do conhecimento organizacional é composto pelas seguintes fases:

- compartilhamento do conhecimento tácito. Esta fase corresponde ao conhecimento que está na mente dos indivíduos, rico e inexplorado, que precisa ser transmitido / compartilhado entre os demais colaboradores. Contudo esta é uma tarefa crítica, pois não é fácil compartilhar o conhecimento tácito entre vários indivíduos com diferentes históricos, perspectivas e motivações. As emoções e sentimentos também precisam ser compartilhados para que se crie um sentimento de confiança mútua. Para que isto seja possível é necessário que se possibilite um campo, um ambiente no qual possa existir a interação e o diálogo. As equipes autoorganizadas facilitam a criação de conhecimento por meio da variedade de requisitos dos colaboradores que experimentam a redundância e compartilham suas interpretações da intenção da organização. A gerência pode possibilitar o caos criativo fazendo com que esta equipe interaja com o ambiente acumulando conhecimentos tácitos e explícitos;

- criação de conceitos. Nesta fase o conhecimento tácito é compartilhado e é convertido em conhecimento explícito, por meio de metáforas e modelos na forma de um novo conceito. Quando um modelo mental compartilhado é criado no campo de interação, a equipe auto-organizada expressa esse modelo por meio do diálogo e da reflexão contínuos. Este modelo mental é verbalizado em palavras e cristalizado em conceitos explícitos. Este fase corresponde à externalização. Este processo de conversão pode ser facilitado pelo uso de métodos de raciocínio como dedução e indução. Os conceitos são criados por meio do diálogo. A autonomia facilita para que os colaboradores possam convergir seus pensamentos em uma direção. A variedade de requisitos auxilia a equipe a ter diferentes ângulos e perspectivas do problema. A flutuação e o caos auxiliam a mudar a maneira de pensar, uma quebra de paradigmas e, por fim a redundância permite que o modelo mental compartilhado seja melhor cristalizado; 
- justificação de conceitos. Nesta fase, o conceito criado anteriormente passa por um julgamento com o objetivo de avaliar sua importância para a organização. Cabe à organização conduzir esta verificação, de maneira que os conceitos gerados estejam alinhados à estratégia organizacional. É importante que a gerência esteja comprometida e engajada em definir os critérios de justificação alinhados à estratégia organizacional. Nesta fase, a redundância de informações auxilia na diminuição de mal-entendidos e interpretações errôneas quanto à intenção organizacional;

- construção de arquétipo ou protótipo. Depois de justificado os conceitos são transformados em arquétipos ou protótipos que são a materialização do conceito justificado. Protótipo é utilizado em caso de novos produtos e para serviços ou inovação, um mecanismo operacional é considerado arquétipo. Em qualquer dos casos trata-se da combinação de conhecimentos recém criados e já existentes. Esta fase é considerada complexa sendo necessária a cooperação dinâmica entre os vários departamentos. A variedade de requisitos e a redundância facilitam esse processo. A intenção pode servir como ferramenta de convergência entre o knowhow e as tecnologias e para promover a cooperação. A autonomia, a flutuação e o caos criativo não são tão relevantes neste processo;

- difusão interativa do conhecimento. Nesta última fase o conhecimento é disseminado para a organização como um todo e em certos casos, até para o ambiente externo. É um processo atualizado continuamente. Para que o processo funcione com eficácia é importante que as unidades da organização tenham autonomia para poder aplicar seus conhecimentos de outras áreas. O rodízio de pessoal possibilitado pela flutuação interna permite que novos conhecimentos sejam difundidos, bem como redundância e a variedade de requisitos. Além disso, a difusão do conhecimento pode agir como um mecanismo de controle para saber o que deve e o que não deve ser compartilhado.

Reconhecida a importância da criação do conhecimento organizacional é necessário que este conhecimento seja compartilhado para que se gerem novos produtos, processos e serviços. 


\section{COMPARTILHAMENTO DE CONHECIMENTO}

As organizações têm conhecimento disseminado e compartilhado entre todos; entretanto, existem também diversos estoques ou conjuntos de conhecimento pertencentes somente a indivíduos, pequenos grupos ou áreas funcionais. As organizações buscam codificar e simplificar esse conhecimento de indivíduos e grupos para torná-lo acessíveis a toda a organização (OLIVEIRA JÚNIOR, 2000). A valorização do ser pensante na organização cria um novo contexto relacional onde a aprendizagem acontece pelas trocas de conhecimento, pelas vivências, pela execução de tarefas que exigem participação de grupos, e não mais o trabalho individualizado (CELADON, 2005). As experiências vivenciadas pelos colaboradores precisam ser transmitidas, pois o compartilhamento é vital para o sucesso das organizações e deve ser feito com rapidez e eficiência a toda a organização. "As idéias causam maior impacto quando são amplamente compartilhadas, e não quando mantidas em poucas mentes" (GARVIN, 2000, p. 68). Compartilhamento do conhecimento segundo Lin (2007) é considerado a cultura de interação social onde ocorrem as trocas de experiências e habilidades. Para Ipe (2003) o compartilhamento é basicamente $o$ ato de disponibilizar o conhecimento aos outros para que este possa ser utilizado. Para Bartol e Svrivastava (2002) é o compartilhamento de informações, idéias, sugestões e experiências organizacionalmente relevantes do indivíduo com outros, um componente chave dos sistemas de Gestão do Conhecimento. E a principal vantagem do compartilhamento é que as idéias e habilidades compartilhadas com alguém não são perdidas e sim dobradas (SVEIBY, 1998). Compartilhar significa trocar, difundir, combinar conhecimento criado tanto no individual como no coletivo, em decorrência de interações entre pessoas e grupos que alcancem toda a organização, até que o conhecimento seja institucionalizado e incorporado às rotinas, processos, práticas e normas organizacionais (OLIVEIRA; ALVES FILHO, 2008).

O desafio, porém está em como compartilhar o conhecimento e como facilitar esse compartilhamento. De acordo com Davenport e Prusak (1998) o compartilhamento acontece quando a organização contrata pessoas perspicazes e deixa que estas pessoas conversem entre si. A questão já conhecida é que o conhecimento tácito é de difícil transferência e de que o compartilhamento é uma 
tarefa difícil. Por este motivo, as organizações devem facilitar o compartilhamento. É preciso criar processos e orientação e/ou de aprendizado para que os conhecimentos tácitos que são importantes na organização não fiquem concentrados em uma única pessoa (DAVENPORT; PRUSAK, 1998). Segundo Nonaka e Takeuchi (1997, p. 69), "o segredo para a aquisição do conhecimento tácito é a experiência. Sem alguma forma de experiência compartilhada, é extremamente difícil para uma pessoa projetar-se no processo de raciocínio do outro indivíduo".

Von Krogh, Ichijo e Nonaka (2001, p. 17) apontam que "a capacitação do conhecimento deve ser vista de maneira circular; objetivar sempre a ampliação do potencial de criação do conhecimento." Para isto, apresentam cinco capacitadores do conhecimento que são atividades que afetam positivamente a criação do conhecimento e preparam o ambiente para o compartilhamento. São eles:

- capacitador 1- Instilar a visão do conhecimento - as organizações têm dificuldade de estabelecer qual conhecimento precisarão no futuro para tomar decisões. A visão do conhecimento, de acordo com os autores, envolve um mapa mental de três áreas. $\mathrm{O}$ mundo em que as organizações vivem, o mundo em que elas devem viver e o conhecimento que precisam buscar e criar. Por meio destes três mapas é possível identificar as áreas de especialização da organização, identificar situações positivas em que deveriam viver proporcionando motivação aos colaboradores e processos para chegar do presente ao futuro em relação ao conhecimento, identificando quais conhecimentos devem buscar. Este capacitador possibilita a capacidade de "prever" o desempenho e sucesso futuro da organização;

- capacitador 2 - Gerenciar conversas - este capacitador apresenta uma das principais maneiras de compartilhar e criar conhecimento - as conversas, ou seja, os relacionamentos entre os colaboradores. Por meio de conversas os colaboradores expõem suas idéias e refletem sobre diversos pontos de vista. Neste momento ocorre a socialização, compartilhando conhecimento tácito para conhecimento tácito. Von Krogh, Ichijo e Nonaka (2001) apresentam alguns princípios para nortear a socialização. São eles: estimular a participação de todos da organização, estabelecer normas de etiqueta para que as conversas não sejam dispersas, conduzir as conversas de maneira apropriada a solução dos problemas e, fomentar uma linguagem inovadora para a criação de novos conhecimentos. Criar espaços e 
ocasiões de encontro dentro ou fora da organização para que as pessoas possam interagir informalmente pode ser um meio de fomentar o compartilhamento. Estes eventos também podem ser importantes para manter o espírito de equipe e o comprometimento (MUSSI; ANGELONI, 2004);

- capacitador 3 - Mobilizar ativistas do conhecimento - Para Von Krogh, Ichijo e Nonaka (2001, p. 13) o ativista do conhecimento é um "gerente dotado de ampla visão social e intelectual, além de experiência nos detalhes das operações da empresa", alguém que possa conectar as iniciativas cognitivas externas e internas, e mobilizar os trabalhadores de toda a organização para usar o conhecimento de maneira mais eficaz. Este capacitador tem como objetivo estabelecer pessoas, grupos ou setores que irão coordenar e facilitar o processo de criação de conhecimento. Estes ativistas são responsáveis pelo comprometimento do processo de criação, pois irão não apenas coordenar e estimular o processo, como transmitir os novos conhecimentos e disseminá-los para toda a organização;

- capacitador 4 - Criar o contexto adequado - para que o conhecimento seja compartilhado na organização é importante que exista um ambiente propício para que exista este compartilhamento. A estrutura organizacional deve ser trabalhada bem como a cultura organizacional para propiciar o compartilhamento. Um aspecto importante que deve existir neste ambiente é a facilidade de comunicação entre os departamentos, unidades o que torna possível a troca de informações, experiências e resultados (CELADON, 2005). Para Von Krogh, Ichijo e Nonaka (2001) o contexto capacitante é um dos principais fatores que impulsionam a criação do conhecimento, este contexto é chamado de "ba" que significa o contexto ideal para a criação do conhecimento, espaço propício para o constante compartilhamento. A palavra tem origem japonesa e a tradução aproximada é de local onde acontece um fato. É um contexto compartilhado para novos relacionamentos, podendo servir como fundação para a criação do conhecimento. Fornece sustentação para o conhecimento individual e/ou coletivo (OUTI; STRAUHS, 2004). O "ba"é importante para acumular e compartilhar o conhecimento tácito (STEWART, 2002). Von Krogh, Ichijo e Nonaka (2001) esclarecem que o "ba" é um espaço compartilhado, que caracteriza-se por uma rede de interações;

- capacitador 5 - Globalizar o conhecimento local - este último capacitador tem como objetivo transmitir o conhecimento a toda organização. Este depende 
diretamente dos quatro anteriores, pois a visão do conhecimento concentra a atenção nos conhecimentos fundamentais; as conversas são o meio para compartilhar; os ativistas auxiliam na coordenação das atividades e difundem o conhecimento; e o contexto adequado define as formas de compartilhamento de acordo com as estratégias, cultura e valores da organização (VON KROGH; ICHIJO; NONAKA, 2001).

Os mesmos autores apontam que existe uma relação entre os capacitadores do conhecimento e a criação do conhecimento organizacional onde existem interações que facilitam a criação do conhecimento nas organizações, impulsionando a inovação e a competitividade das mesmas. Entre os capacitadores, pôde-se notar que dois deles afetam todas as fases de criação: o gerenciamento de conversas e a criação do contexto adequado, que afetam diretamente a criação de conhecimento.

Reconhecida a importância da criação e do compartilhamento do conhecimento organizacional, Terra (2001 e 2005) aponta sete dimensões que propõe um papel central da gestão das organizações para criar condições propícias à criação e ao compartilhamento do conhecimento.

\section{SETE DIMENSÕES DO CONHECIMENTO SEGUNDO TERRA}

A abordagem apresentada por Terra (2001) aponta sete dimensões da gestão do conhecimento que propõe um papel central da gestão das organizações para a criação de condições propícias ao compartilhamento e criação do conhecimento (Figura 1). As sete dimensões apresentadas são:

- fatores estratégicos e o papel da alta administração - apresenta os aspectos que devem ser considerados pela alta administração, os conhecimentos e metas. É papel da gerência criar a necessidade de inovação na organização, de clarificação da estratégia e definição de metas. A alta administração também tem papel indispensável na definição dos campos do conhecimento, possibilitando que os colaboradores focalizem os esforços e estejam engajados no aprendizado contínuo (TERRA, 2001). Ou seja, um alto nível de consenso sobre as habilidades e competências é muito importante para a Gestão do Conhecimento, porque facilita o 
desenvolvimento das estratégias de negócio que alavancam estes ativos (TERRA, 2007);

- cultura organizacional - A cultura organizacional representada, em parte, por sua missão e valores deve ser ancorada e construída por meio de atos simbólicos e ações da alta administração que valorizam e destacam fatos, notícias e pessoas que exemplificam os valores perseguidos. Vários estudos têm mostrado que o papel fundamental da alta administração em empresas líderes é o de fomentar a missão e o conjunto de valores da organização e como estes se alinham à estratégia e sistemas gerenciais (TERRA, 2007). A cultura deve ser voltada ao aprendizado contínuo, estimulando a criação de uma identidade da organização propícia a exploração de novas ideias e criação e compartilhamento. É papel da alta administração desenvolver uma cultura organizacional que estimule a inovação, a experimentação e o aprendizado contínuo. É importante que o aprendizado, a colaboração e o compartilhamento sejam considerados parte do dia a dia dos colaboradores e as estratégias e objetivos estratégicos foquem a criação do conhecimento organizacional. Ou seja, o ambiente organizacional deve ser propício ao compartilhamento. Algumas características são: os colaboradores se sentirem estimulados pelas suas atividades, conversas entre colaboradores de mesmo e de diferentes níveis hierárquicos, relações informais, tempo hábil para o aprendizado, foco no longo prazo e não apenas na área de trabalho de cada um, abertura, colaboração e flexibilidade para trocar experiências de sucesso e erros, divulgação de resultados, e, discussão de valores da organização como algo relevante (TERRA, 2001);

- estrutura organizacional - apresenta modelos de estruturas flexíveis que favorecem a inovação e o aprendizado, estimulando o trabalho em equipes. Algumas novas estruturas estão sendo baseadas na multidisciplinaridade e alto grau de autonomia (TERRA, 2001). Além disso, os espaços de trabalhos ou leiautes estão sendo percebidos como capazes de influenciar a criatividade, o aprendizado organizacional e o clima para inovação nas empresas. Cada vez mais, os conceitos de espaços fechados e símbolos de status relacionados à hierarquia perdem lugar para conceitos abertos, humanísticos, ecológicos e não hierárquicos, que facilitam os contatos informais e a comunicação em todos os sentidos. Outra abordagem é a de skunk works (espaços propositalmente informais e desconectados do ambiente 
corporativo) para emular o ambiente inovativo de pequenas empresas. Em escritórios ou ambientes mais high-tech, é comum se observar espaços absolutamente desconectados com a realidade de trabalho, como salas de ginástica, quadra de esportes, salas de jogos e salas de meditação (TERRA, 2007);

- recursos humanos - Nos modelos organizacionais da Era Industrial havia uma grande preocupação na descrição detalhada de cada um dos cargos da organização. Na Era do Conhecimento toma-se uma visão muito mais focada na pessoa e no conjunto de suas habilidades, competência e experiências (TERRA, 2007). Os critérios para contratação de novos colaboradores tem um impacto importante no futuro das organizações, por este motivo é necessário que a criação do conhecimento seja um dos pontos considerados na seleção. Algumas características que se destacam para prática de recursos humanos associados à criação de conhecimento, atrair e manter pessoas com habilidades, comportamentos e competências que adicionem e incrementem os fluxos de conhecimento, estimular comportamentos de aprendizado e fortalecimento de core competencies, como realizações de planos de carreira e treinamentos, estabelecer esquemas de remuneração que estejam associados à aquisição de competências individuais, da equipe e da empresa, pois o que mantém as pessoas unidas são seus interesses comuns tanto de aprendizado como de desenvolvimento pessoal, criar um grau de identificação dos colaboradores com a organização, expresso por um sentimento de orgulho, estimulando a inovação, aumentando a confiança e criando um ambiente mais cooperativo e propício ao compartilhamento e criação de conhecimento pois é necessário para isto muito contato humano, intuição, conhecimento tácito, cooperação e explicitação (TERRA, 2001);

- sistemas de informação - apresenta a tecnologia da informação como elemento facilitador ao processo de compartilhamento do conhecimento, pois, apesar dos grandes avanços para auxílio aos processos de geração, difusão e armazenamento de informações e de conhecimento, o papel das relações pessoais e de conhecimento tácito para gerar aprendizado organizacional e as relações de um ambiente propício ao compartilhamento com confiança, transparência e colaboração, dependem exclusivamente dos indivíduos (TERRA, 2001). Há, portanto, necessidade de garantir que o acesso à informação seja facilitado, porém não forçando esta política caso não se justifique do ponto de vista do negócio da 
organização. Nas empresas intensas em conhecimento, os sistemas de informação são essenciais para que as etapas de um ciclo de conhecimento organizacional sejam processadas. Isto requer sistemas que facilitem a identificação, acesso, organização, distribuição seletiva de informações relevantes e pertinentes ao trabalho de cada colaborador da organização (TERRA, 2007);

- mensuração de resultados - A mudança para a Era do Conhecimento demanda os resultados em termos de desenvolvimento de competências da organização, de divisões, departamentos ou indivíduos sejam avaliados com a mesma prioridade que os resultados financeiros e operacionais. Desta forma, as organizações de ponta e líderes que realmente colocam a questão da gestão do conhecimento e dos ativos intangíveis como algo estratégico, demandam de seus executivos e gerentes um acompanhamento detalhado da evolução das competências-chave para o negócio. Um dos esforços importantes de mensuração para organizações baseadas em conhecimento é aquele associado à avaliação da evolução das competências dos colaboradores (TERRA, 2007);

- aprendizado com o ambiente - O monitoramento do entorno organizacional realizado de maneira deliberada, formal, organizada, coletiva e seletiva é uma atividade crítica para organizações que querem ter um posicionamento estratégico pró-ativo. As organizações que compreendem melhor sua posição no mercado e conseguem avaliar sua evolução de forma regular têm mais condições de ter sucesso (TERRA, 2007). 
Figura 1 - Sete Dimensões da Gestão do Conhecimento

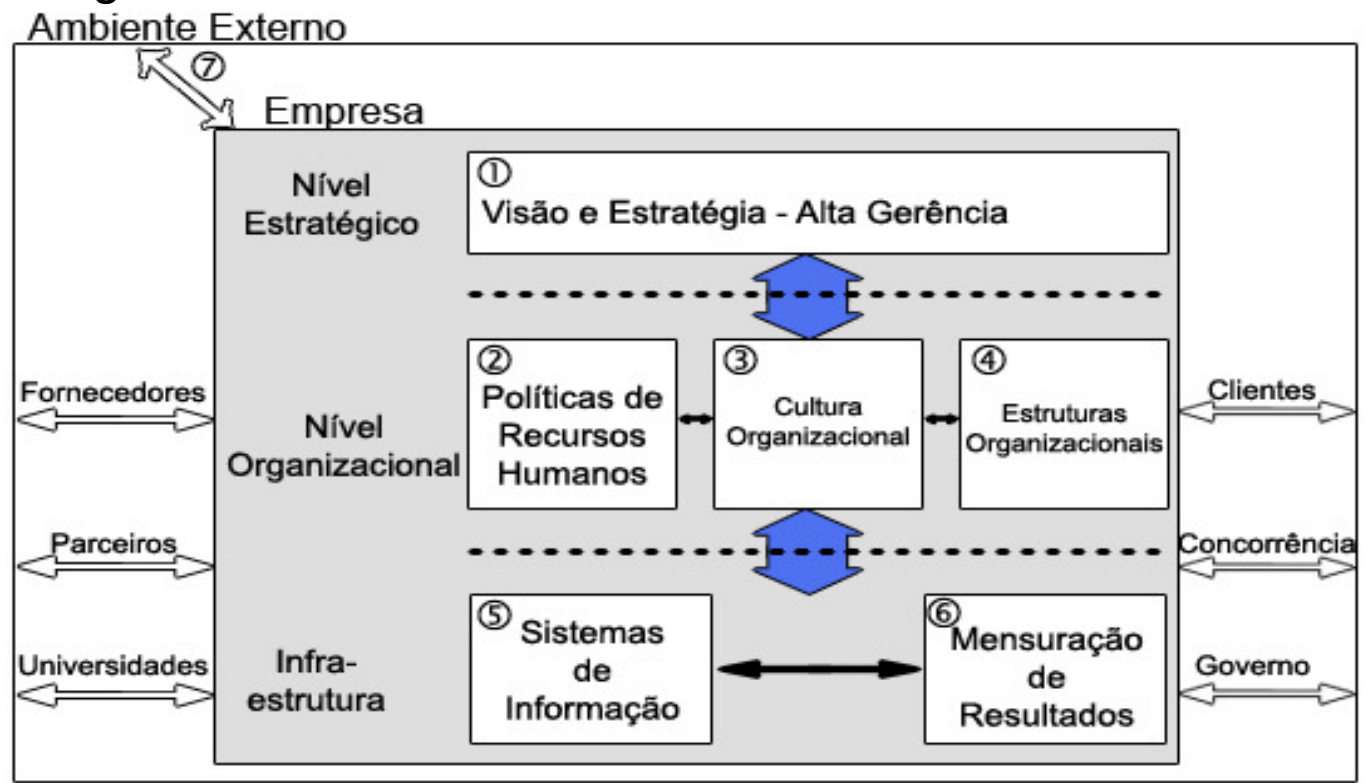

Fonte: Terra $(2001,2007)$.

Considerando as sete dimensões propostas, fica claro que o capital humano, formado pelos valores, habilidades e atitudes e experiências dos colaboradores, é o fator mais importante e propulsor de criação de conhecimento e criação de valor para as organizações. Considerando esta afirmativa, as organizações devem, portanto, cultivar ambientes para troca de conhecimento entre os seus colaboradores e fomentar a inovação, o compartilhamento, a motivação, a comunicação e o desenvolvimento de habilidades tanto profissionais como pessoais. É importante que a cultura esteja disseminada para todos, que os sucessos e fracassos sejam analisados e que os ensinamentos estejam registrados e sejam repassados. As idéias causam maior impacto quando são disseminadas rapidamente e não quando ficam apenas em poucas mentes (GARVIN, 2000).

Conclui-se que cada vez mais as organizações estão considerando a criação de conhecimento como fator de competitividade. Porém, isto não basta para o sucesso. É necessário que as organizações realmente disseminem e promovam a criação de conhecimento. É importante que exista um processo sistematizado e consciente para que a criação de conhecimento possa ser efetiva e gere resultados positivos. É necessário que este conhecimento seja compartilhado para que se gerem novos produtos, processos e serviços. 


\section{PROCEDIMENTOS METODOLÓGICOS}

A pesquisa caracterizou-se como qualitativa exploratória e descritiva utilizando as técnicas da pesquisa bibliográfica, levantamento documental, observação direta e, como método de pesquisa o estudo de caso. A instituição selecionada para a pesquisa empírica foi a Federação das Indústrias do Estado do Paraná - FIEP-PR. A escolha se deu pela vantagem de ser uma instituição sediada em Curitiba / PR que atua com projetos prospectivos, tendo inclusive uma área funcional específica para tais projetos e pela possibilidade de observação direta do projeto em questão. O trabalho de campo reuniu e organizou um conjunto de informações que foram coletadas, inicialmente, por meio de análise do referencial teórico, posteriormente, pela análise da documentação da organização e da observação do projeto.

Em um primeiro momento foi feito um diagnóstico da organização, e realizadas várias visitas à equipe dos Observatórios com o objetivo de conhecer a organização, ambiente da pesquisa e, identificar um projeto em que fosse possível realizar o presente estudo de caso. O acesso à documentação da organização foi possível, também, devido ao contato direto da pesquisadora com a equipe gestora do projeto. Foi necessária uma adaptação da documentação levantada, para o propósito da presente pesquisa. Entre os principais arquivos utilizados para a pesquisa destacam-se os documentos enviados aos especialistas participantes referentes ao projeto. A análise foi feita pela percepção da pesquisadora com base na documentação do projeto, nas reuniões com a equipe do projeto e na observação do ambiente. Para tanto, foram criadas categorias, com base nas sete dimensões propostas por Terra (2001), ou seja, fatores estratégicos e o papel da alta administração, cultura e valores organizacionais, estrutura organizacional, administração de recursos humanos, sistemas de informação, mensuração de resultados e aprendizado com o ambiente. Para visualização do resultado obtido da análise da observação e documentação da organização foi utilizada a ferramenta gratuita para criação de mapas conceituais - FreeMind, versão 0.9.0 RC 4.

O projeto Perfis Profissionais para o Futuro da Indústria utiliza, em uma de suas etapas, da metodologia "painel de especialistas", que de acordo com SENAI (2005, p. 5) é uma reunião conduzida de um grupo seleto de pessoas, especialistas 
em certo tema de discussão, para criar conhecimento antecipando o futuro. Para observação do ambiente, dos 11 painéis a serem realizados de acordo com as temáticas identificadas do projeto (agroalimentar, saúde, turismo, biotecnologia, papel e celulose, produtos de consumo, meio ambiente, plástico, metal mecânico, energia e tecnologias da informação e comunicação), 7 deles já tinham acontecido no momento do início da presente pesquisa.

O resultado da análise, apresentado na seqüência, foi desenvolvido pelo cruzamento das informações coletadas nos documentos e com base na observação.

\section{RESULTADOS: APRESENTAÇÃO E ANÁLISE}

A análise do projeto foi feita pela percepção da pesquisadora com base nos documentos, nas reuniões feitas com a equipe do projeto e na observação do ambiente. Nesse sentido foram criadas categorias, seguindo as sete dimensões propostas por Terra (2001) com o intuito de identificar se o projeto está alinhado e se a organização está preocupada em manter um ambiente propício à criação e compartilhamento do conhecimento entre seus colaboradores. As Figuras 2 e 3 resumem e ilustram, na forma de mapa conceitual, os resultados obtidos no estudo em relação às Sete Dimensões da Gestão do Conhecimento. 
Karoline Aparecida Scroch Sato; Helena Nunes Silva; Isabela Drago A gestão do conhecimento sob a perspectiva das sete dimensões: o caso do projeto perfis profissionais para o futuro da indústria

Figura 2 - Análise do Ambiente e da Documentação da Organização - Parte

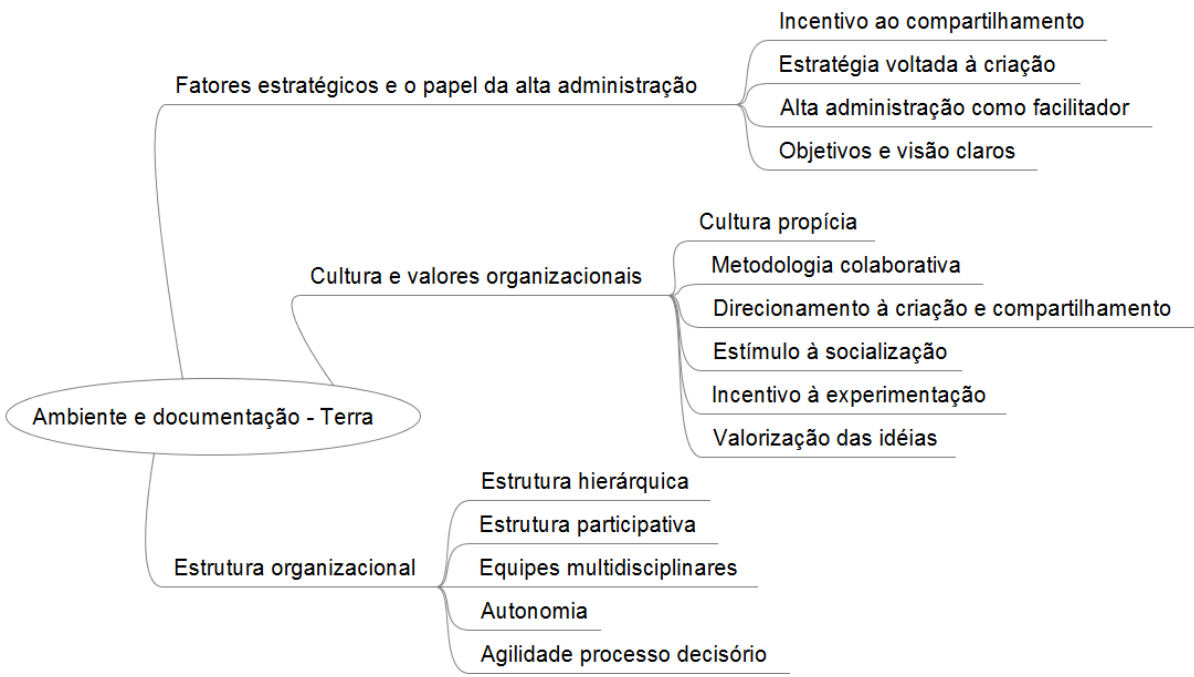

Fonte: Elaborado pelas autoras

Figura 3 - Análise do Ambiente e da Documentação da Organização-Parte

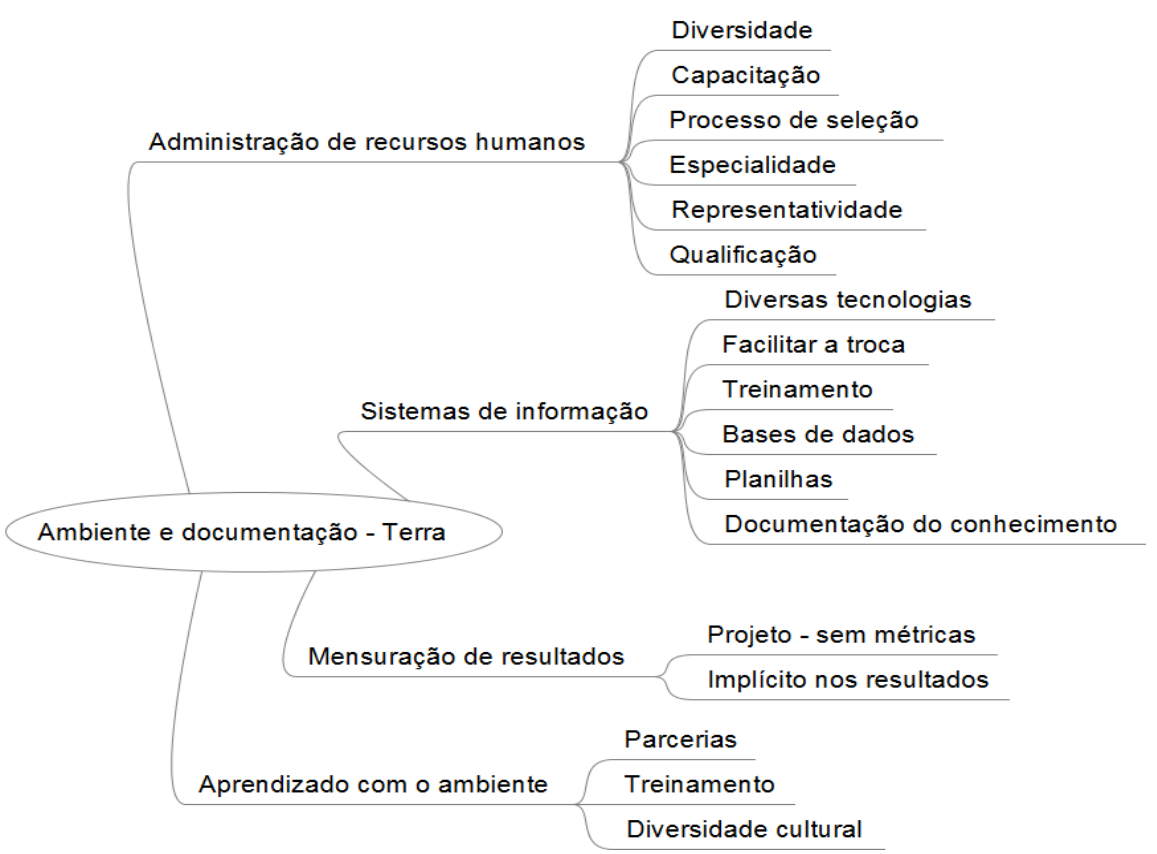

Fonte: Elaborado pelas autoras

\subsection{Fatores estratégicos e o papel da alta administração}

O papel da alta administração no contexto atual, apresenta um caráter de ação, de alavancagem de habilidades e incentivos para enfrentar riscos (TERRA, 
2001). Pode-se identificar, observando o desenrolar dos painéis de especialistas, que a equipe gestora do projeto está engajada em proporcionar aos participantes, ou seja, os especialistas de cada painel, este incentivo ao compartilhamento. O projeto está bem definido e foca nos campos do conhecimento, os setores identificados como promissores para o futuro da indústria. Portanto, pode-se concluir que a estratégia do projeto está voltada à criação do conhecimento, pois é por meio do processo de conversão e compartilhamento do conhecimento que acontece durante a realização dos painéis que se cria o conhecimento. O papel da alta administração, ou seja, gestores do projeto, também está alinhado à criação do conhecimento, atuando como um facilitador, ou ativista do conhecimento, auxiliando as discussões para o compartilhamento, tornando claros os objetivos e a visão do projeto e definido metas.

\subsection{Cultura e valores organizacionais}

$\mathrm{Na}$ dimensão dois, Terra (2001) afirma que a missão e os valores da organização devem ser amplamente conhecidos e incorporados e deve existir um elevado sentimento de confiança entre a organização e seus colaboradores. Visualiza-se neste sentido, que a organização tem a cultura propícia à criação e ao compartilhamento, principalmente pelo fato de que a organização trabalha com uma metodologia colaborativa, na qual todos cooperam e ocorre o compartilhamento e a criação do conhecimento. É possível visualizar o direcionamento da organização. Muitos projetos estimulam a socialização, ou seja, a cultura é propícia ao compartilhamento. Dentro do projeto específico ao estudo de caso também verificase que a cultura é para compartilhar, a equipe gestora, trazendo a cultura da organização, promove a inovação, a experimentação e o aprendizado dos participantes. Há liberdade para tentar e falhar, inclusive em um documento power point apresentado durante os painéis, são mostradas afirmações de grandes especialistas que se equivocaram, trazendo a idéia de que até grandes especialistas se equivocam, estimulando a experimentação. Existe uma valorização das idéias e as pessoas são estimuladas a pensar em longo prazo. O leiaute estabelecido para a realização dos painéis permite a criação e o compartilhamento do conhecimento. 


\subsection{Estrutura organizacional}

Com relação à terceira dimensão, Terra (2001) propõe que a estrutura organizacional deve implementar um modelo flexível de gestão. Verifica-se que na organização existe uma estrutura hierárquica, porém os colaboradores também são responsáveis pelo processo, um modelo de estrutura participativa. No projeto identifica-se uma estrutura baseada no trabalho de equipes multidisciplinares com alto grau de autonomia, estimulado pela equipe gestora. São criadas equipes temporárias com grande autonomia. A primeira equipe durante a realização dos painéis é estabelecida pela equipe gestora do projeto, porém em momento posterior as equipes são misturadas, tendo de haver consenso entre todos. As decisões são tomadas com nível mínimo de burocracia, pois cada decisão é debatida com todos os participantes, o que torna o processo decisório ágil.

\subsection{Administração de recursos humanos}

As organizações devem focar o desenvolvimento com base nas pessoas. Deve haver uma busca pela diversidade, o planejamento da carreira e o estímulo ao aprendizado (TERRA, 2001). Identifica-se que a organização analisada procura fazer uma seleção dos recursos humanos levando em consideração a diversidade. $A$ organização também procura promover a constante capacitação da equipe, por meio de treinamentos internos e externos e, também por parcerias com instituições nacionais e internacionais. Tais atitudes tornam facilitadas as fases de geração, difusão, armazenamento e compartilhamento do conhecimento individual para o coletivo. Com relação ao projeto em questão, existe um processo de seleção bastante rigoroso dos especialistas. São analisadas a diversidade e representatividade dos especialistas na indústria, academia, governo e terceiro setor. Os especialistas são selecionados por pesquisa a bases de dados, principalmente Lattes, de maneira com que todos tenham alta qualificação profissional e notório conhecimento do setor analisado. O aprendizado é estimulado pela ampliação de contatos e interação com os demais participantes. 


\subsection{Sistemas de informação}

Com relação à dimensão cinco - sistemas de informação, Terra (2001) aponta que o uso de tecnologias da Informação pode facilitar o processo de criação e compartilhamento do conhecimento, porém também é necessário o estímulo à comunicação eficiente em todos os níveis da organização com acesso às bases de conhecimento. Neste sentido, verifica-se que a organização analisada utiliza diversas tecnologias de informação e comunicação para facilitar a troca entre os colaboradores e até mesmo com o público externo, por meio do site institucional, blogs e twiters indicados. A escolha dos sistemas nem sempre é amigável aos colaboradores, porém sempre são realizados treinamento para capacitar ao uso das ferramentas. Durante os painéis são utilizadas planilhas para facilitar a construção do resultado e, também, a posterior difusão, tornando possível a criação de uma memória do projeto e facilitando a recuperação dos conhecimentos criados. Existe grande incentivo com relação à documentação do conhecimento criado durante os painéis. A equipe gestora elabora esta documentação.

\subsection{Mensuração de resultados}

A penúltima dimensão - a mensuração de resultados é, de acordo com Terra (2001), uma preocupação que a organização deve ter com relação a procedimentos para mensuração sob diversas perspectivas, financeira, operacional, estratégica e de divulgação. Com relação ao projeto, verifica-se que não existem indicadores explícitos. A mensuração dos resultados fica implícita no retorno obtido por meio da mobilização dos especialistas de cada setor, formando uma rede articulada, pela integração do tecido industrial e pela apropriação dos resultados pela sociedade.

\subsection{Aprendizado com o ambiente}

O aprendizado com o ambiente é, segundo Terra (2001), a preocupação permanente da organização em aprender por meio do relacionamento com clientes, empresas, universidades e institutos de pesquisa. Verifica-se que a organização constantemente promove parcerias com várias instituições sejam privadas, públicas, 
de ensino e pesquisa ou institutos. Freqüentemente promove treinamentos para os colaboradores tendo como parceria universidades e centros de ensino. Com relação ao projeto, a própria dinâmica de trazer especialistas, gerando uma diversidade cultural rica, possibilita o aprendizado com o ambiente. A parceria feita com o instituto OPTI - Observatório de Prospectiva Tecnológica Industrial também possibilita esta relação com atores externos e promove o aprender a aprender.

\section{CONSIDERAÇÕES FINAIS}

O objetivo deste artigo foi analisar a gestão do conhecimento na perspectiva das Sete Dimensões de Terra. Assim, percebeu-se que o embasamento teórico forneceu elementos para estabelecer a metodologia de análise da documentação da organização e as observações realizadas junto à Equipe Gestora do Projeto.

Pelos resultados obtidos, pode-se perceber que a organização está alinhada às Sete Dimensões da Gestão do Conhecimento, propostas por Terra (2001, 2005, 2007) e, portanto, cria condições propícias ao compartilhamento e à criação de conhecimento.

A alta administração preocupa-se em divulgar, de forma clara e transparente, a visão e os objetivos da organização. Além disso, ela é vista como facilitadora a criação e ao compartilhamento de informações, experiências e conhecimentos entre os membros do projeto.

A cultura organizacional apresenta-se propícia ao compartilhamento pela utilização de uma metodologia com estímulo à socialização, experimentação e valorização das ideias.

A estrutura, apesar de ser hierárquica incentiva à participação, com equipes multidisciplinares que trabalham com autonomia.

A administração dos recursos humanos (Dimensão 4) tem como base um processo de seleção voltado a especialidades e qualificações diversas, com constantes capacitações de seus colaboradores. Percebe-se pelos resultados que a Equipe do Projeto está alinhada aos elementos apontados na teoria, ou seja, "diversidade de perfis está associada de forma crescente a ambientes mais criativos. Pessoas com diferentes backgrounds, experiências e educação formal trazem 
perspectivas diferentes para a solução de problemas e geração de novos insights" (TERRA, 2007, p. 68).

No que se refere aos sistemas de informação, a organização utiliza diversas tecnologias para facilitar a troca de informações e conhecimentos e busca treinar os colaboradores para uso destas tecnologias. Como afirma Terra "uma das tendências mais recentes em organizações líderes é a constituição de espaços virtuais para a troca de informações com diversos tipos de atores externos." (TERRA, 2007, p. 30).

Para avaliação dos resultados do projeto não existem métricas definidas, mas a medição dos resultados está implícita em todas as atividades do projeto. Pode-se inferir que os procedimentos para medição dos resultados ainda não estão totalmente integrados, unificados, padronizados e disseminados.

Além disso, pelos exemplos encontrados na literatura, acredita-se que o envolvimento na formalização de processos desenvolvidos e novos conhecimentos que podem ser criados propiciarão destaque e valor aos colaboradores perante a equipe e a organização como um todo.

Em relação ao aprendizado com o ambiente se dá por meio de parcerias, capacitações e da própria diversidade cultural e de formação da equipe. Estes resultados vão ao encontro das colocações de Terra (2007, p. 104) "[...] mesmo as maiores organizações estão valorizando o papel das parcerias para seu desempenho. Em grande medida, organizações líderes estão no centro de grandes redes de parcerias."

Pelos resultados do estudo acredita-se que a equipe do Projeto Prospecção de Perfis Profissionais, ligada ao SESI/PR e o SENAI/PR tem um ambiente propício à criação e compartilhamento de conhecimento o qual é fundamental na prospecção de oportunidades de inovação e na geração de respostas às demandas e necessidades socioindustriais para o futuro da indústria paranaense.

Pode-se sugerir como propostas de trabalhos futuros, o aprofundamento de cada uma das sete dimensões incluindo a visão não só da equipe gestora do projeto como também dos especialistas envolvidos na elaboração dos resultados. Sugerese também, a criação de um modelo de gestão do conhecimento dentro da equipe do Projeto Perfis Profissional para o Futuro da Indústria, com o objetivo de aprimorar e também solucionar as lacunas identificadas. Pelos resultados do artigo, percebeuse a necessidade de análise das sete dimensões da Gestão do Conhecimento 
propostas por Terra (2007) às demais equipes, bem como desenvolver uma metodologia de forma sistêmica a todo o Sistema FIEP para implementar a Gestão do Conhecimento baseada nas dimensões propostas. Dessa maneira, espera-se que este artigo lance luzes sobre o tema e que a partir dos resultados obtidos, outros estudos possam ser realizados de forma mais profunda.

\section{REFERÊNCIAS}

BARTOL, Kathryn M.; SRIVASTAVA, Abhishek. Encouraging knowledge sharing: the role of organizational reward systems. Journal of Leadership \& Organizational Studies, Thousand Oaks, v. 9, n. 1, p. 64-77, 2002.

CARVALHO, H. G. Texto Básico da Disciplina Gestão de informação tecnológica (Draft). Curitiba: CEFET-PR, 2000

CELADON, Kleber Luís. O compartilhamento do conhecimento no âmbito intraempresarial: um estudo de caso. 2005. 96 f. Dissertação (Mestrado em Tecnologia) - Universidade Tecnológica Federal do Paraná, Curitiba.

DAVENPORT, Thomas H.; PRUSAK, Laurence. Conhecimento empresarial: como as organizações gerenciam o seu capital intelectual. Rio de Janeiro: Campus, 1998.

\section{FEDERAÇÃO DAS INDÚSTRIAS DO ESTADO DO PARANÁ - FIEP. Perfis} profissionais do futuro: metal mecânico. Curitiba: SESI/SENAI, 2010.

GARVIN, David A. Construindo a organização que aprende. In: HARVARD BUSINESS REVIEW. Gestão do conhecimento. Rio de Janeiro: Campus, 2000. p. $50-81$.

GODET, Michel. A “caixa de ferramentas” da prospectiva estratégica. 2000. Disponível em: <http://www.cnam.fr/lipsor/lips/conferences/outils.php>. Acesso em: 20 dez. 2009.

IPE, Minu. Knowledge sharing in organizations: a conceptual framework. Human Resource Development Review, Thousand Oaks, v. 2, n. 4, p. 337-359, Dec. 2003.

LIN, Hsiu-Fen. Effects of extrinsic and intrinsic motivation on emplouee knowledge sharing intentions. Journal of Information Science, Thousand Oaks, v. 33, n. 2, p. 135-149, 2007.

MUSSI, Clarissa Carneiro; ANGELONI, Maria Terezinha. Compartilhamento do conhecimento no contexto de projetos de tecnologia da informação. In: ANGELONI, Maria Terezinha. Gestão do conhecimento no Brasil: casos, experiências e práticas de empresas públicas. Rio de Janeiro: Qualitymark, 2004. Cap. 5. 
NONAKA, Ikujiro. A empresa criadora de conhecimento. In: HARVARD BUSINESS REVIEW. Gestão do conhecimento. Rio de Janeiro: Campus, 2000. p. 27-49.

NONAKA, Ikujiro; TAKEUCHI, Hirotaka. Criação de conhecimento na empresa. Rio de Janeiro: Campus, 1997.

OLIVEIRA JÚNIOR, Moacir de Miranda. Competências essenciais e conhecimento na empresa. In: FLEURY, Maria Tereza Leme; OLIVEIRA JÚNIOR, Moacir de Miranda.Gestão do conhecimento, aprendizagem e competências estratégicas. São Paulo: Atlas, 2000. p. 121-156

OLIVEIRA, Rezilda Rodrigues; ALVES FILHO, Bartolomeu de Figueiredo. Contexto de compartilhamento do conhecimento: o caso do Serpro-Recife. In: ANGELONI, Maria Terezinha. Gestão do conhecimento no Brasil: casos, experiências e práticas de empresas públicas, QUALITYMARK, 2008. Cap. 4.

OUTI, Nilton Sadao; STRAUHS, Faimara Rocio. Visão nacional do processo de criação do conhecimento japonês: estudo de caso AirCon do Brasil. In: KM BRASIL CONGRESSO BRASILEIRO, 2004, São Paulo. Anais... São Paulo: KM Brasil, 2004. v. 1.

SANTOS, Antonio Raimundo et al. Gestão do conhecimento: uma experiência para o sucesso profissional. Curitiba: Champagnat, 2001.

SANTOS, Marcio de Miranda et al. Prospecção de tecnologias de futuro: métodos, técnicas e abordagens. Parcerias Tecnológicas, Brasília, n.19, p.189-230, dez. 2004.

STEWART, Thomas A. A riqueza do conhecimento: o capital intelectual e a nova organização. Rio de Janeiro: Campus, 2002.

SVEIBY, Karl Erick. A nova riqueza das organizações: gerenciando e avaliando patrimônios de conhecimento. Rio de Janeiro: Campus, 1998.

TERRA, José Cláudio Cyrineu. Gestão do conhecimento: o grande desafio empresarial. São Paulo: Negócio, 2001.

TERRA, José Cláudio Cyrineu. Gestão do conhecimento: o grande desafio empresarial. Rio de Janeiro: Elsevier, 2005.

TERRA, José Cláudio Cyrineu. Gestão do conhecimento: sete dimensões e 100 práticas gerenciais. São Paulo: TerraFórum Consultores, 2007.

TONET, Helena Correa; DA PAZ, Maria das Graças Torres. Um modelo para o compartilhamento de conhecimento no trabalho. Revista de Administração Contemporânea, Curitiba, v. 10, n. 2, p. 75-94, abr./jun. 2006.

VON KROGH, Georg Von; ICHIJO, Kazuo; NONAKA, Ikujiro. Facilitando a criação de conhecimento: reinventando a empresa com o poder da inovação contínua. Rio de Janeiro: Campus, 2001. 


\title{
Title
}

The Knowledge Management under the perspective of the seven dimensions: a case study of the Project Professional Profiles for Industry Future

\begin{abstract}
Introduction: Organizations that uses prospective studies, are intense in the creation and sharing of knowledge and one of the main challenges is to make the individual knowledge collective.
\end{abstract}

Objective: To analyze, grounded on the seven dimensions of knowledge as proposed by Terra $(2001,2005)$, the alignment of the project to that dimensions of knowledge management, in order to enable an environment favorable to the creation and sharing of knowledge.

Methodology: A Descriptive study based on a case study.

Results: The senior management is seen as a facilitator; that the organizational culture that promotes sharing by using a methodology to encourage socialization, testing and promotion of ideas; that despite the hierarchical structure, there are incentives to participate; that there is a selection process designed to different specialties and qualifications, with constant training of its workforces; that the organization uses several technologies to facilitate the exchange of information and knowledge; that there are no defined metrics to evaluate project results and, finally, that learning about the environment is through partnerships, training and cultural diversity.

Conclusions: It concluses that the team project has an environment favorable to creation and sharing of knowledge which is essential for the opportunities prospecting for innovation and generating in responses to the socioindustriais demands and needs for the future of the Paraná's industry.

Keywords: Knowledge sharing. Knowledge creation. Knowledge Management.

\section{Título}

La gestión del conocimiento bajo la perspectiva de las siete dimensiones: el caso del proyecto Perfiles profesionales para el futuro de la Indústria.

\section{Resúmen}

Introducción: Organizaciones que actuan en estudios prospectivos son intensas en cuanto creación y compartimento del conocimiento y uno de los principales desafíos es tornar colectivo el conocimiento individual.

Objectivo: Analizar por medio de las siete dimensiones del conocimiento propuestas por Terra $(2001,2005)$, el alineamiento del proyecto "Perfiles profesionales para el futuro de la Indústria" posibilitando un ambiente faborable a la creación y al intercambio de conocimientos.

Metodología: Investigación descriptiva fundamentada en un estudio de caso.

Resultados: La alta administración actua como agente facilitador; la cultura organizacional 

profissionais para o futuro da indústria

proporciona el compartimento estimulando la socialización, experimentación y valoración de las ideas; a pesar de la existencia de una estructura jerárquica, la participación es estimulada; existe un proceso de selección dirigido a distintas especialidades y calificaciones, con capacitaciones constantes; la organización utiliza distintas tecnologías facilitando el intercambio de información y conocimiento; no existen padrones definidos para la evaluación de los resultados y, finalmente, el aprendizaje con el ambiente se produce por medio de asociaciones, entrenamientos y de la propia diversidad cultural.

Conclusiones: Se concluye que el equipo del proyecto cuenta con un ambiente favorable a la creación y compartimiento de conocimiento que es fundamental en la búsqueda de oportunidades de innovación y generación de respuestas a las demandas y necesidades socioindustriales para el futuro de la industria del Paraná.

Palabras clave: Gestión del conocimiento Compartimiento del conocimiento. Creación del conocimiento.

Recebido em: 12.09 .2012

Aceito em: 10.05.2013 